\title{
More glass; more challenges!
}

\author{
Jan Belis $(\mathbb{D}$ - Christian Louter $[$ - Jens Henrik Nielsen $(\mathbb{D}$ - \\ Jens Schneider $\mathbb{D}$ - Mauro Overend $\mathbb{D}$
}

Published online: 28 April 2018

(C) Springer International Publishing AG, part of Springer Nature 2018

Launching a peer-reviewed journal is a challenge. While the few first online-first articles of Glass Structures and Engineering had already been downloaded 676 times by the end 2015, we saw download numbers explode to over 16,000 in 2016 and further increase to almost 25,000 in 2017. These great numbers illustrate further the growing impact this journals starts to have within the structural glass community and we are grateful for this to our readers, authors, reviewers, editors and publisher.

While such wide distribution of valuable knowledge certainly helps to answer some questions, at the same time it raises many others, constantly pushing the scientific, technological, design and engineering limits.

\section{J. Belis $(\varangle)$}

Ghent University, Ghent, Belgium

e-mail: Jan.Belis@ugent.be

\section{J. Belis}

Eindhoven University of Technology, Eindhoven,

The Netherlands

\section{Louter}

Delft University of Technology, Delft, The Netherlands e-mail: Christian.Louter@TUDelft.nl

\section{J. H. Nielsen}

Technical University of Denmark, Lyngby, Denmark e-mail: jhn@byg.dtu.dk

\section{J. Schneider}

Technical University of Darmstadt, Darmstadt, Germany e-mail: schneider@ismd.tu-darmstadt.de

M. Overend

University of Cambridge, Cambridge, UK

e-mail:mo318@cam.ac.uk
Therefore, condensed in no less than 17 original articles, this issue brings to the fore a number of important challenges in glass engineering. These are concentrated on repair and strength of glass, connections of structural glass components, glass design projects, specific actions on glass structures, robustness of load-bearing glass components and systems, and experimental methods.

The first challenge relates to repair and strength of glass. To this end, Datsiou et al. (2018) investigate the strength recovery of annealed glass by treating visible flaws with resins, polishing and acids, while Kinsella and Persson (2018) propose a numerical method for the analysis of fracture statistics of glass and simulations of a double ring bending test. Next, Bonati et al. (2018) and Pourmoghaddam and Schneider (2018) focus in particular on heat-treated glass, dealing respectively with a micro-mechanically motivated strength model and an experimental investigation into the fragment size of tempered glass.

The second challenge aims at the development, design and modelling of connections in structural glass and façade applications. Katsivalis et al. (2018) demonstrate by means of a strength evaluation and failure prediction how adhesive bonds outperform a bolted solution for two benchmark designs of glass-to-steel shear connections. Van Lancker et al. (2018) and IoannidouKati et al. (2018) focus on the mechanical behaviour of glass-to-steel bonds under monotonic and cyclic loading, investigating respectively continuous adhesive connections, and laminated connections with Transpar- 
ent Structural Silicone Adhesive (TSSA). Cavitation in the latter material is further studied by Drass et al. (2018). Furthermore, Bedon and Amadio (2018a) give numerical evidence that the use of special mechanical connectors between the building structure and the glazing facade can activate the latter as an effective Tuned Mass Damper system to protect the building structure from extreme events such as seismic actions and explosions.

The third challenge brings us to the real world of novel glass design projects. The case included in this issue reveals the all-glass entrance pavilion for an office building in Madrid by Teixidor et al. (2018).

Challenge number four consists of the proper understanding of specific actions and their combinations on glass structures. Specifically for insulating glass units, Bedon and Amadio (2018b) present a linear formulation for the Ultimate Limit State design of glass elements under combined loads, while Nicklisch et al. (2018) investigate cold-bending of timber-glass composite elements.

Finally, the fifth and last challenge covers experimental testing and the design or improvement of experimental, analytical and numerical methods. Baidjoe et al. (2018) and Aurik et al. (2018) respectively apply experimental methods to assist in the design of glass masonry arches where the interaction between glass and interlayer is important. Furthermore, Botz et al. (2018) present a sensitivity analysis for the determination of the interlayer shear modulus in laminated glass using a torsional test, which may be used complementary to common small-scale tests such as dynamic mechanical thermal analysis. Also Schuster et al. (2018) focus on interlayers, as they use DynamicalMechanical-Thermal-Analysis (DMTA) and Differential Scanning Caliometry (DSC) to characterize an Ethylene-vinyl acetate (EVA) interlayer for numerical incorporation into state-of-the-art Finite-ElementSoftware. Finally, Martens et al. (2018) demonstrate experimentally how hyperstatic reinforced glass beams may benefit from membrane action in a post-fracture state.

We hope you enjoy reading and we look forward to your continuous support in reading, publishing and distributing our journal within the glass community.

\section{References}

Aurik, M., Snijder, A., Noteboom, C., Nijsse, R., Louter, C.: Experimental analysis on the glass-interlayer system in glass masonry arches. Glass Struct. Eng. (2018). https:// doi.org/10.1007/s40940-018-0068-7

Baidjoe, et al.: Calculation methods of glass parapets in aluminium parapet clamping profiles. Glass Struct. Eng. (2018). https://doi.org/10.1007/s40940-018-0075-8

Bedon, C., Amadio, C.: Glass facades under seismic events and explosions: a novel distributed-TMD design concept for building protection. Glass Struct. Eng. (2018a). https://doi. org/10.1007/s40940-018-0058-9

Bedon, C., Amadio, C.: A linear formulation for the ULS design of glass elements under combined loads: application to IGUs. Glass Struct. Eng. (2018b). https://doi.org/10.1007/ s40940-018-0060-2

Bonati, A., Occhiuzzi, A., Pisano, G., Royer-Carfagni, G., et al.: A micro-mechanically motivated model for the strength of heat-treated glass. Glass Struct. Eng. (2018). https://doi.org/ 10.1007/s40940-018-0071-z

Botz, M., Kraus, M.A., Siebert, G.: Sensitivity analysis for the determination of the interlayer shear modulus in laminated glass using a torsional test. Glass Struct. Eng. (2018). https://doi.org/10.1007/s40940-018-0067-8

Datsiou, K.C., Hall, D., Overend, M.: Repair of soda-lime-silica glass. Glass Struct. Eng. (2018). https://doi.org/10.1007/ s40940-018-0064-y

Drass, M., Kolupaev, V.A., Schneider, J., Kolling, S.: On cavitation in transparent structural silicone adhesive: TSSA. Glass Struct. Eng. (2018). https://doi.org/10.1007/ s40940-018-0061-1

Ioannidou-Kati, A., Santarsiero, M., de Vries, P., Teixeira de Freitas, S., Nijsse, R., Louter, C.: Mechanical behaviour of transparent structural silicone adhesive (TSSA) steel-toglass laminated connections under monotonic and cyclic loading. Glass Struct. Eng. (2018). https://doi.org/10.1007/ s40940-018-0066-9

Katsivalis, I., Thomsen, O.T., Feih, S., Achintha, M.: Strength evaluation and failure prediction of bolted and adhesive glass/steel joints. Glass Struct. Eng. (2018). https://doi.org/ 10.1007/s40940-018-0070-0

Kinsella, D.T., Persson, K.: A numerical method for analysis of fracture statistics of glass and simulations of a double ring bending test. Glass Struct. Eng. (2018). https://doi.org/10. 1007/s40940-018-0063-z

Martens, K., Caspeele, R., Belis, J.: Experimental investigation into the effects of membrane action for continuous reinforced glass beam systems. Glass Struct. Eng. (2018). https://doi.org/10.1007/s40940-018-0076-7

Nicklisch, F., Greulich, T., Weller, B.: A numerical and experimental approach to cold-bent timber-glass composite elements. Glass Struct. Eng. (2018). https://doi.org/10.1007/ s40940-018-0069-6 
Pourmoghaddam, N., Schneider, J.: Experimental investigation into the fragment size of tempered glass. Glass Struct. Eng. (2018). https://doi.org/10.1007/s40940-018-0062-0

Schuster, et al.: Investigations on the thermorheologically complex material behaviour of the laminated safety glass interlayer Ethylene-Vinyl-Acetate. Glass Struct. Eng. (2018). https://doi.org/10.1007/s40940-018-0074-9

Teixidor, C., Torres, J., Estupiñá, L.: All-glass entrance pavillion for an office building in Madrid. Glass Struct. Eng. (2018). https://doi.org/10.1007/s40940-018-0059-8
Van Lancker, B., De Corte, W., Belis, J.: Mechanical properties of continuous adhesive glass-steel connections under monotonic and cyclic loading. Glass Struct. Eng. (2018). https:// doi.org/10.1007/s40940-018-0072-y

Publisher's Note Springer Nature remains neutral with regard to jurisdictional claims in published maps and institutional affiliations. 